\title{
BMJ Open Costs and effects of on-demand treatment of hereditary angioedema in Italy: a prospective cohort study of 167 patients
}

\author{
Carlo Federici, ${ }^{1}$ Francesca Perego, ${ }^{2}$ Ludovica Borsoi, ${ }^{1}$ Valentina Crosta, ${ }^{2}$ \\ Andrea Zanichelli, ${ }^{2}$ Antonio Gidaro, ${ }^{2}$ Rosanna Tarricone, ${ }^{3}$ Marco Cicardi ${ }^{2}$
}

To cite: Federici C, Perego F, Borsoi L, et al. Costs and effects of on-demand treatment of hereditary angioedema in Italy: a prospective cohort study of 167 patients. BMJ Open 2018;8:e22291. doi:10.1136/ bmjopen-2018-022291

- Prepublication history and additional material for this paper are available online. To view please visit the journal (http:// dx.doi.org/10.1136/bmjopen2018-022291).

CF and FP contributed equally.

Received 14 February 2018

Revised 5 June 2018

Accepted 25 June 2018

A Check for updates

C C Author(s) (or their employer(s)) 2018. Re-use permitted under CC BY-NC. No commercial re-use. See rights and permissions. Published by BMJ.

${ }^{1}$ Centre for Research on Health and Social Care Management (CeRGAS), SDA Bocconi

University, Milan, Italy

${ }^{2}$ Department of Biomedical and Clinical Sciences, "Luigi Sacco" University Hospital, University of Milan, Milan, Italy

${ }^{3}$ Government, Health and Non Profit Division, SDA Bocconi University, Milan, Italy

Correspondence to Dr Francesca Perego; francescappe@gmail.com

\section{ABSTRACT}

Objectives To explore treatment behaviours in a cohort of Italian patients with hereditary angioedema due to complement C1-inhibitor deficiency (C1-INH-HAE), and to estimate how effects and costs of treating attacks in routine practice differed across available on-demand treatments.

Design Cost analyses and survival analyses using attacklevel data collected prospectively for 1 year.

Setting National reference centre for C1-INH-HAE.

Participants 167 patients with proved diagnosis of C1-INH-HAE, who reported data on angioedema attacks, including severity, localisation and duration, treatment received, and use of other healthcare services.

Interventions Attacks were treated with either icatibant, plasma-derived C1-INH (pdC1-INH) or just supportive care. Main outcome measures Treatment efficacy in reducing attack duration and the direct costs of acute attacks. Results Overall, 133 of 167 patients (79.6\%) reported 1508 attacks during the study period, with mean incidence of 11 attacks per patient per year. Only $78.9 \%$ of attacks were treated in contrast to current guidelines. Both icatibant and pdC1-INH significantly reduced attack duration compared with no treatment (median times from onset 7, 10 and 47 hours, respectively), but remission rates with icatibant were $31 \%$ faster compared with $\mathrm{pdC1}$ INH (HR 1.31, 95\% Cl 1.14 to 1.51). However, observed treatment behaviours suggest patterns of suboptimal dosing for pdC1-INH. The average cost per attack was $€ 1183$ (SD €789) resulting in €1.58 million healthcare costs during the observation period (€11912 per patient per year). Icatibant was $54 \%$ more expensive than pdC1INH, whereas age, sex and prophylactic treatment were not associated to higher or lower costs.

Conclusions Both icatibant and pdC1-INH significantly reduced attack duration compared with no treatment, however, icatibant was more effective but also more expensive. Treatment behaviours and suboptimal dosing of pdC1-INH may account for the differences, but further research is needed to define their role.

\section{INTRODUCTION}

Hereditary angioedema is most commonly due to genetic complement C1-inhibitor deficiency (C1-INH-HAE). Its prevalence is uncertain,

\section{Strengths and limitations of this study}

- This study exploits data on 1508 hereditary angioedema attacks, prospectively collected over 1 year from 133 patients, out of a total sample of 167 patients.

- A number of statistical models have been explored to account for different assumptions in the data structure.

- In the absence of direct evidence from clinical studies, this study uses real-world data to estimate the relative effectiveness of plasma-derived $\mathrm{C} 1$-inhibitor and icatibant.

- Limitations of this study include that, since treatment for acute attacks was mostly self-administered at home, there is no way to control for patients seeking treatments inappropriately or in the absence of a true hereditary angioedema attack.

- The data did not include information on weight, and other patients characteristics, limiting the interpretation of the observed treatment patterns and the role of these characteristics on treatment costs and outcomes.

with estimates ranging between 1 in 10000 and 1 in 150000 persons $^{1-4}$ worldwide, whereas in Italy, minimum calculated prevalence was found to be $1: 64000 .{ }^{5}$ C1-INH-HAE is characterised by periodic self-limiting oedema of the extremities, face, genitals, gastrointestinal and upper airway mucosa. All symptoms can cause temporary disability and are life-threatening because of asphyxiation when located at the larynx. Their pathophysiology is well defined ${ }^{6}$ : C1-INH controls the activity of contact system enzymes, factor XIIa and plasma kallikrein. C1-INH deficiency facilitates contact system activation and local release of the vasoactive peptide bradykinin, responsible for oedema formation. ${ }^{7}$ Frequency and severity of angioedema recurrences are highly variable and represent the main drivers of disease burden. In fact, due to the invalidating nature 
of attacks, individuals with C1-INH-HAE suffer from severe deterioration in their quality of life. In addition, at the societal level, C1-INH-HAE causes substantial productivity losses due to missed time at school or work for patients and their caregivers, as well as long-term consequences for education attainment and careers. ${ }^{8-10}$ Therapies for on-demand treatment (ODT) of C1-INH-HAE attacks are available,${ }^{11-17}$ and existing clinical guidelines recommend patients to treat all attacks at onset. ${ }^{18}$ ODTs reduce the time a patient has angioedema and the risk of death for life-threatening attacks. ${ }^{19}$ In Italy, two plasma derived and one recombinant C1-INH (Berinert, Cinryze, Ruconest), and the bradykinin receptor antagonist icatibant (Firazyr) are registered for ODT. However, Ruconest is not reimbursed by the Italian National Healthcare System, and its use remains marginal. Icatibant is delivered as prefilled syringe to be administered at a fixed dose of $30 \mathrm{mg}$, whereas plasma-derived C1-INH (pdC1-INH) is delivered in vials of $500 \mathrm{IU}$ for a weight-based dose of $20 \mathrm{IU} / \mathrm{Kg}$. The costs of ODTs are considerable ranging from $€ 560$ for 1 phial of pdC1-INH to $€ 1695$ for icatibant. Patients who do not reach adequate disease control on ODT can be switched to long-term prophylaxis (LTP), ${ }^{18}$ with attenuated androgens or two times per week infusions of Cinryze. ${ }^{1720}$ Attenuated androgens have minimal cost, but side effects limit their use $^{21}$ whereas the yearly cost for Cinryze prophylaxis in Italy is about $€ 150000$ per patient, and can be prescribed only to patients requiring four or more ODTs per month. ${ }^{22}$

Availability of treatments for C1-INH-HAE have played a fundamental role in reducing the health and societal burden of the disease ${ }^{23}$; however, their high cost has raised several concerns among healthcare payers worldwide. ${ }^{102425}$ Indeed, budget constrained healthcare systems are increasingly concerned about demonstrating the value for money of new treatments as a must-have condition for coverage and reimbursement decisions.

However, to date there is still little knowledge on a number aspects that are relevant to make informed decisions for C1-INH-HAE treatments. These include (1) the average number of angioedema recurrences in patients with C1-INH-HAE, (2) treatment behaviours during attacks and (3) the relative effectiveness of available ODTs and their related costs. This study aims to fill this gap by analysing a population of patients with C1-INH-HAE in their real life followed prospectively for 1 year at the Milan angioedema centre in Italy.

\section{MATERIAL AND METHODS \\ Patients}

This is a prospective observational study conducted at Milan angioedema centre between 1 January and 31 December 2014. We evaluated 167 patients with C1-INH-HAE, who accurately recorded angioedema symptoms in diaries of attacks, which were subsequently validated by physicians. Diagnosis was based on family and/or personal history of recurrent angioedema, and on laboratory levels of C1-INH $<50 \%$ of normal.
According to guidelines, all patients had ODT available at home and were recommended to use the treatment at onset of angioedema attacks. ${ }^{18}$ Treatments with Cinryze and Ruconest cover less than $5 \%$ of the total ODTs in Italy and were not considered for the study.

The following data about angioedema attacks were recorded in a dedicated diary by patients every time that they experienced an attack: (1) time of onset of symptoms (defined as the time when patients recognise the presence of an angioedema); (2) time of complete resolution (defined as the time when patients recognise that angioedema is not present any more); (3) attack location (peripheral, abdominal, facial, laryngeal); (4) attack severity, defined as impairment on daily activities (mild for no impairment, moderate for partial impairment and severe for complete impairment); (5) medication(s) and dose(s) used for treating the attack, and time of administration; and (6) need for other medical assistance, diagnostic tests or emergency department visits.

No data were recorded that allowed to quantify productivity losses at the societal level such as days missed at work or school.

\section{Statistical analysis}

Patients and attacks characteristics

Patients' characteristics for the whole sample were summarised by reporting mean and median values for continuous data and frequencies (percentages) for categorical data. Attack data were reported for the whole sample and grouped by first-line treatment; ${ }^{2}$ tests with a significance level at $\mathrm{p}<0.05$ were applied to check for differences in the characteristics of attacks between ODTs.

\section{Treatment effectiveness}

Two different times to attack resolution were considered, starting from either the onset of symptoms or the time of administration of the first-line ODT. While the first one provides a measure of the relative effectiveness between treatment alternatives, the second allows for comparisons with attacks not being treated. This second time span also implicitly includes potential differences in the time to treatment between ODT drugs that may originate from the different routes of administration.

Standard Kaplan-Meier ${ }^{26}$ estimates were used to estimate the mean and median times to resolution. Attack data were required to have complete information on the time (date and hour) of symptoms onset, the time of treatment administration and at least the day when the attack was reported as resolved. If the hour of the attack resolution was missing, the attack was considered censored at the latest time between the date of treatment administration and 00:00 hours of the reported day of resolution. Comparisons between treatments alternatives have been evaluated using log-rank test statistics, adjusted for attack site and attack severity. In addition, Cox proportional hazard models were fitted to estimate the contribution of a set of variables to the rate of attack resolution. The variables to be included in the model have been chosen using 


\begin{tabular}{lrl}
\hline Table 1 & Tariffs and sources for cost data \\
\hline Resource use & $\begin{array}{c}\text { Total } \\
\text { tariff }(\boldsymbol{\epsilon})\end{array}$ & $\begin{array}{l}\text { ICD-9-CM codes and } \\
\text { other sources }\end{array}$ \\
\hline Ambulatory visits & 16.79 & 89.01 .2 \\
\hline Blood and urine tests & 49.28 & $91.49 .2 ; 90.62 .2 ; 90.27 .1 ;$ \\
& $90.04 .5 ; 90.09 .2 ; 90.10 .4 ;$ \\
& $90.43 .2 ; 90.14 .3 ; 90.29 .2 ;$ \\
& $90.23 .5 ; 90.40 .4 ; 90.37 .4 ;$ \\
& $90.11 .4 ; 90.15 .4 ; 90.16 .3 ;$ \\
& $90.72 .3 ; 90.42 .1 ; 90.38 .4 ;$ \\
& $89.66 ; 90.44 .3$
\end{tabular}

\begin{tabular}{|c|c|c|}
\hline \multicolumn{3}{|l|}{ Diagnostic tests } \\
\hline ECG & 11.62 & 89.52 \\
\hline Rx abdomen & 19.37 & 88.19 \\
\hline $\begin{array}{l}\text { Superior abdomen } \\
\text { ultrasound }\end{array}$ & 60.43 & 88.76 .1 \\
\hline $\begin{array}{l}\text { Total abdomen } \\
\text { ultrasound }\end{array}$ & 43.90 & 88.74 .1 \\
\hline MRI abdomen & 187.13 & 89.95 .2 \\
\hline $\begin{array}{l}\text { Emergency department } \\
\text { visit }\end{array}$ & 109.38 & $\begin{array}{l}€ 23 \text { assumed for } \\
\text { emergency acceptance } \\
\text { visit+codes: } \\
99.22 ; 91.49 .2 ; 90.62 .2 ; \\
90.27 .1 ; 90.04 .5 ; 90.10 .4 ; \\
90.29 .2 ; 90.40 .4 ; 90.37 .4 ; \\
90.15 .4 ; 90.10 .2 ; 90.16 .3 ; \\
90.72 .3 ; 89.52 ; 88.19 ; \\
88.76 .1 ; 89.66\end{array}$ \\
\hline \multicolumn{3}{|l|}{ Treatment } \\
\hline $\begin{array}{l}\text { C1-inhibitor (500 } \\
\text { unit) }\end{array}$ & 560 & $\begin{array}{l}\text { Ex-factory national } \\
\text { reimbursement price }\end{array}$ \\
\hline Icatibant (30 mg) & 1695 & $\begin{array}{l}\text { Ex-factory national } \\
\text { reimbursement price }\end{array}$ \\
\hline
\end{tabular}

a step function to find the model specification with the lowest Akaike information criterion. ${ }^{27}$ The proportional hazard assumption has been investigated by calculating Pearson product-moment correlations and by visual inspection of residuals plotted against attack time.

\section{Cost analysis}

For the cost analysis of C1-INH-HAE attack, the perspective of the Italian National Health Service was taken. Consumption of resources in the database was identified through ICD-9-CM codes and linked to national tariffs for ambulatory services ${ }^{28}$ as detailed in table 1 . Drug costs have been estimated from official national reimbursement prices that represent the maximum price to which local hospitals can purchase treatment drugs. ${ }^{29} 30$

Since not all patients registering an attack sought treatment, the cost data present a non-negative mass at 0 costs. To account for this, two-part models were used, which analyse the data in two separate steps. First, a logistic regression on all data was used to estimate the probability of seeking treatment, adjusted for patients' sex and age, attack site and attack severity; subsequently, a conditional regression was performed on attack data with positive cost values, evaluating the contribution of each predictor on the total attack cost. In this second step, we adjusted for patients age and sex, attack site and severity, ODT drug, and time from onset of symptoms to treatment.

Eight different models were fitted using both frequentist and Bayesian approaches. First, to account for the typical skewness of cost data, the second part of the model was parametrised using either a log-normal or a gamma distribution. ${ }^{31}$ Second, since each patient recorded multiple attacks during the observation period, different assumptions on the structure of the data were made, by considering either a multilevel structure, accounting for within-patient correlations or a complete pooling of data. $^{32}$ In the first case, two distinct random effects for the intercept were estimated for each part of the model.

For Bayesian models, an initial run of 75000 iterations was considered as 'burn in' (these values were discarded). Two independent chains, starting from randomly assigned values were run, and convergence was monitored by looking at the ratio of the within-chain to between-chain variance to be about one, and by using Heidelberger-Welch ${ }^{33}$ and Gelman-Rubin ${ }^{34}$ diagnostics.

Following the approach proposed by Cooper et al, ${ }^{35}$ retransformation of coefficients in the log-normal models was performed applying a non-parametric retransformation factor known as a 'smearing' estimator, ${ }^{36}$ that avoids efficiency and consistency problems related to the non-normality of the error distribution.

To assess the predictive ability of each model, data were randomly split into a learning sample (90\% of observations), which was used to fit the models, and a test sample ( $10 \%$ of observations), which was used for model validation. The predictive ability of each model was then assessed using the root mean square error (RMSE) criterion for the mean.

All analyses were performed using RStudio (V.3.4.0) and OpenBUGS (V.3.2.3).

\section{Patient involvement}

No patients were involved in setting the research question or the outcome measures, nor were they involved in developing plans for the implementation of the study. No patients were asked to advise on interpretation or writing up of results. The results will be disseminated during the annual meeting of patients of the Italian Angioedema Association and on the dedicated website.

\section{RESULTS}

\section{Descriptive results of the patients reporting attacks in the study period}

Table 2 reports the patient-level characteristics of the sample.

Of all 167 patients included in the study, 34 (20\%) reported no attacks, whereas the remaining 133 registered 1508 angioedema attacks during the observation period. However, a high variability was found across patients, ranging from 1 to 126 attacks (IQR 14). Patients on LTP 
Table 2 General characteristic of patients reporting attacks

\section{Patients reporting angioedema attacks}

( $n=133)$

\begin{tabular}{lc}
\hline Age (years), mean (SD) & $43(16.9)$ \\
\hline Female patients, n (\%) & $85(64)$ \\
\hline $\begin{array}{l}\text { C1-inhibitor deficiency-hereditary angioedema } \\
\text { type I, n (\%) }\end{array}$ & $126(95)$ \\
Patients on long-term prophylaxis*, n (\%) & $29(22)$ \\
\hline Danazol & 15 \\
\hline Stanozolol & 11 \\
\hline Tranexamic acid & 3 \\
No of attacks per patient per year, mean (SD) & $11(16)$ \\
No of attacks per patient per year, median (IQR) & $22(14)$ \\
\hline Frequency of attacks per year, no of patients (\%) & \\
1 & $21(15.8)$ \\
$2-5$ & $41(30.8)$ \\
$6-10$ & $30(22.5)$ \\
\hline $11-20$ & $19(14.3)$ \\
$21-30$ & $9(6.8)$ \\
\hline 30 & $13(9.8)$ \\
\hline
\end{tabular}

*The number includes two patients who reported being on longterm prophylaxis just for 3 and 4 months from their first attack.

accounted for $25 \%$ of all reported attacks. Overall, the distributions of attack frequencies were similar in patients with and without LTP (figure 1A,B, respectively). Particularly, the proportion of patients with $\leq 10$ attacks was $68.8 \%$ for patients not on prophylaxis and $69.0 \%$ for patients on prophylaxis $(69.1 \%$ in the whole sample). No additional data on LTPs were available for patients who reported no attacks during the observation period.

Table 3 summarises the characteristics of attacks and their related treatments. Attacks were more often peripheral $(47.6 \%)$, followed by abdominal attacks $(39.4 \%)$, facial attacks $(6.2 \%)$ and laryngeal attacks $(4.8 \%)$. Of the total number of attacks, $1190(78.9 \%)$ were treated with ODT, of which 704 with pdC1-INH (59.2\% of treated attacks) and 486 with icatibant.

\section{Treatments effectiveness}

When using pdC1-INH, 30\% and $40 \%$ of attacks were treated with a dosage considered appropriate for a weight of 25 and $50 \mathrm{~kg}$, respectively (500 or $1000 \mathrm{IU}$ ). In addition, despite the recommended weight-based dosage, a certain amount of variability was observed within the same patients across attacks (online supplementary file 1). Lastly, for 318 (21\%) attacks, patients received no treatment or just supportive care.

Forty-four attacks $(2.9 \%)$ required a second treatment, and this proportion was found to be higher if the firstline treatment was icatibant compared with pdC1-INH (5.6\% and $2.4 \%$, respectively). Lastly, 131 attacks $(8.7 \%)$ were treated in the emergency department, with all patients discharged within 4 hours. Laryngeal, abdominal and facial attacks were more frequently treated with pdC1-INH compared with icatibant $(\mathrm{p}<0.05)$.

Compared with no treatment, both icatibant and pdC1-INH significantly reduced overall attack times from onset to complete resolution of symptoms ( ${ }^{2} 164$, $\mathrm{p}<0.001$ ) (table 4, figure 2A). However, icatibant showed faster resolution times from treatment administration, compared with pdC1-INH $\left({ }^{2} 10.6, \mathrm{p}=0.001\right)$ (table 4 , figure $2 \mathrm{~B})$.
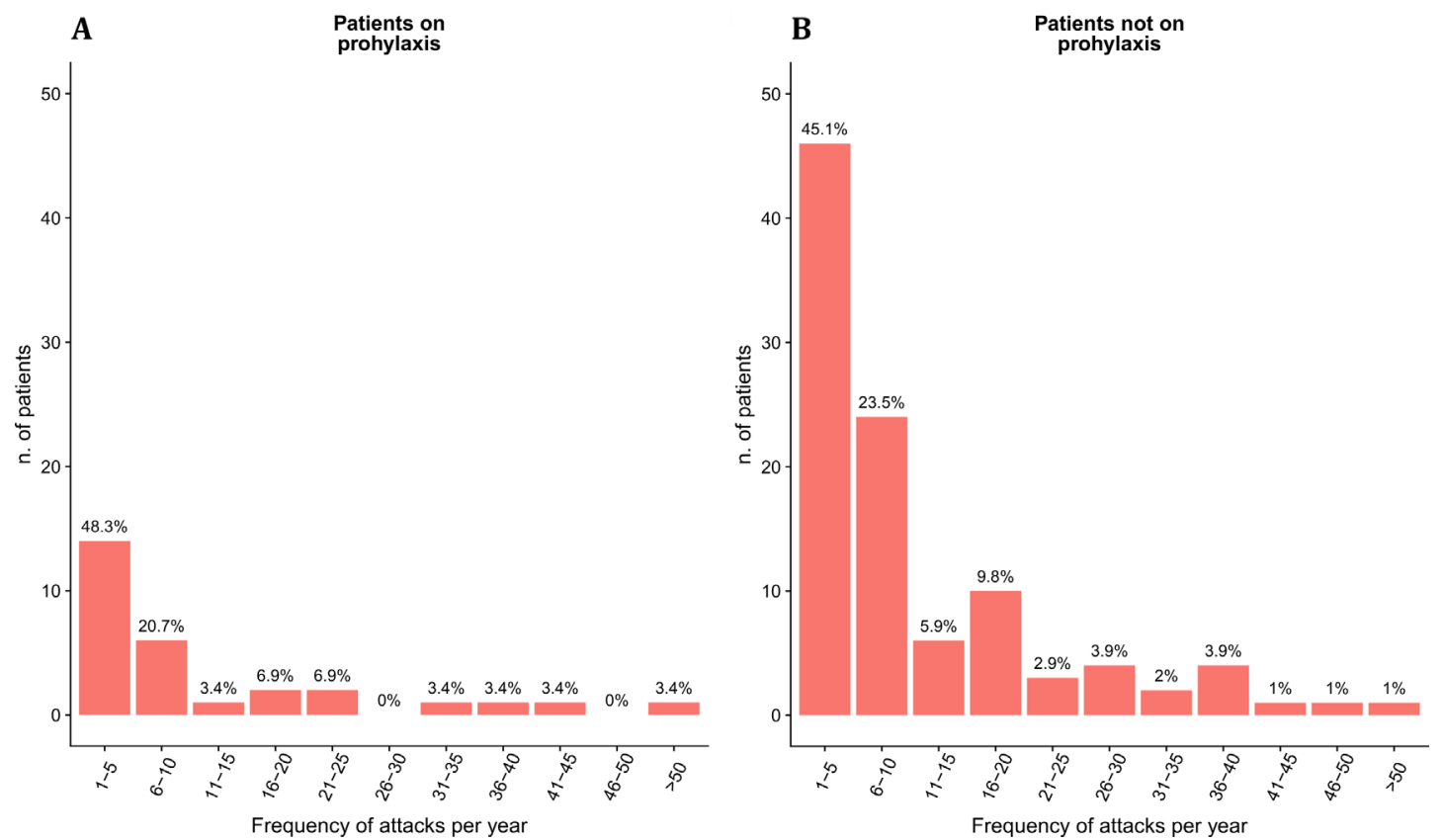

Figure 1 Distribution of attacks per year in the C1-IHN-HAE population with $(\mathrm{A})$ and without (B) long-term prophylaxis. C1IHN- HAE, C1-inhibitor deficiency- hereditary angioedema. 
Table 3 Characteristics of attacks (all attacks and by treatment received)

Total attacks $\mathrm{n}=1508$ pdC1-INH $\mathrm{n}=704$ Icatibant $\mathrm{n}=486$ No treatment $\mathrm{n}=\mathbf{3 1 8}$

\begin{tabular}{|c|c|c|c|c|}
\hline \multicolumn{5}{|l|}{ Location } \\
\hline Throat larynx (\%) & $72(4.8)$ & $50(7.1)^{\star} \dagger$ & $18(3.7)^{\star}$ & $4(1.4)$ \\
\hline Abdominal (\%) & $594(39.4)$ & $279(39.6)^{*} \dagger$ & $236(48.6)^{*}$ & $79(24.9)$ \\
\hline Cutaneous peripheral (\%) & $718(47.6)$ & $287(40.7)^{\star}$ & $207(42.6)^{\star}$ & $224(70.5)$ \\
\hline Face $(\%)$ & $93(6.2)$ & $58(8.2)^{\star} \dagger$ & $25(5.1)$ & $10(3.2)$ \\
\hline Not reported (\%) & $31(2.0)$ & $31(4.4)$ & $0(0)$ & $0(0)$ \\
\hline \multicolumn{5}{|l|}{ Severity } \\
\hline Mild (\%) & $360(23.9)$ & $146(20.7)^{\star}$ & $102(21.0)^{\star}$ & $112(35.2)$ \\
\hline Moderate (\%) & $718(47.6)$ & $344(48.9)$ & $231(47.6)$ & $143(45.0)$ \\
\hline Severe $(\%)$ & $430(28.5)$ & $214(30.4)^{*}$ & $153(31.4)^{*}$ & $63(19.8)$ \\
\hline Second treatment (\%) & $44(2.9)$ & $17(2.4)^{\star}$ & $27(5.6)$ & \\
\hline \multicolumn{5}{|l|}{ Prophylaxis } \\
\hline No (\%) & $1132(75.3)$ & $508(72.2)^{*}$ & $388(79.8)$ & $236(74.2)$ \\
\hline Yes (\%) & $372(24.7)$ & $194(27.8)^{\star}$ & $96(20.2)$ & $82(25.8)$ \\
\hline \multicolumn{5}{|l|}{ Dosage for pdC1-INH } \\
\hline Dose pdC1-INH 500 IU (\%) & & $211(30.0)$ & & \\
\hline Dose pdC1-INH 1000 IU (\%) & & 277 (39.3) & & \\
\hline Dose pdC1-INH 1500 IU (\%) & & $181(25.7)$ & & \\
\hline Dose pdC1-INH 2000 IU (\%) & & $27(3.9)$ & & \\
\hline Dose not reported (\%) & & $8(1.2)$ & & \\
\hline Emergency department admission & $131(8.7)$ & $115(16.3)^{\star} \dagger$ & $6(1.2)^{\star}$ & $10(31.4)$ \\
\hline
\end{tabular}

${ }^{*} \mathrm{P}<0.05$, comparison versus no treatment.

$\dagger \mathrm{P}<0.05$, comparison versus icatibant.

pdC1-INH, plasma derived C1-inhibitor.

The Cox proportional hazard model estimated that remission rates when using icatibant were $31 \%$ faster compared with pdC1-INH (HR 1.31, 95\% CI 1.14 to 1.51) (table 5). Attack severity and attack site were not found to be associated with different remission rates, with the only exception for laryngeal attacks (HR 1.44, 95\% CI 1.07 to 1.95 ). In addition, shorter time to treatment was associated with a small $(2 \%)$ but significant positive effect on remission rates (HR 0.98, 95\% CI 0.97 to 0.99 ), suggesting that each additional hour between onset of symptoms and treatment

Table 4 Mean and median times to complete resolution of attack symptoms

\begin{tabular}{lcc}
\hline Treatment & $\begin{array}{l}\text { Mean time } \\
\text { (SE) }\end{array}$ & $\begin{array}{l}\text { Median time } \\
\text { (95\% Cl) }\end{array}$ \\
\hline $\begin{array}{l}\text { Time from treatment administration } \\
\text { pdC1-INH, plasma derived } \\
\text { C1-inhibitor (pdC1-INH) }\end{array}$ & $14.10(0.88)$ & $7.5(7$ to 8.5$)$ \\
\hline $\begin{array}{l}\text { Icatibant } \\
\text { Time from onset of symptoms }\end{array}$ & $11.60(1.04)$ & $4(3.5$ to 5$)$ \\
\hline No treatment & $50.5(2.42)$ & $47(42$ to 54$)$ \\
\hline pdC1-INH & $18.5(1.09)$ & $10(9$ to 10$)$ \\
\hline Icatibant & $15.3(1.17)$ & $7(6$ to 8$)$ \\
\hline
\end{tabular}

administration would increase the chance of a faster resolution by approximately $2 \%$. Lastly, when comparing attack duration with icatibant and pdC1-INH versus no treatment, remission rates were found to be 2.5 times and 3 times higher (HR 3.16, 95\% CI 2.62 to 3.80; and HR 2.45, $95 \%$ CI 2.05 to 2.93 , respectively) (table 5 ).

\section{Cost analysis}

Total costs during the observation period amounted to $€ 1.58$ million, equivalent to slightly more than $€ 11900$ per patient per year. The average cost for a single attack cost was $€ 1183$ (SD €789) including drug costs, emergency department visits and diagnostic tests.

The complete results of all cost models are reported in the online supplementary file 2 . The model with the best predictive ability, based on RMSE, was a multilevel model with the second regression parameterised as a gamma distribution with a log link (RMSE=389.02).

Patients' sex, age and whether they were on LTP did not significantly influence the cost and were taken out of the model to improve predictive ability and fit.

Drug type was the most relevant cost driver. The unadjusted mean cost per attack was $€ 1069$ (SD €470) with pdC1-INH and $€ 1651$ (SD €469) with icatibant. After controlling for attack site and severity, the cost of treating 
A

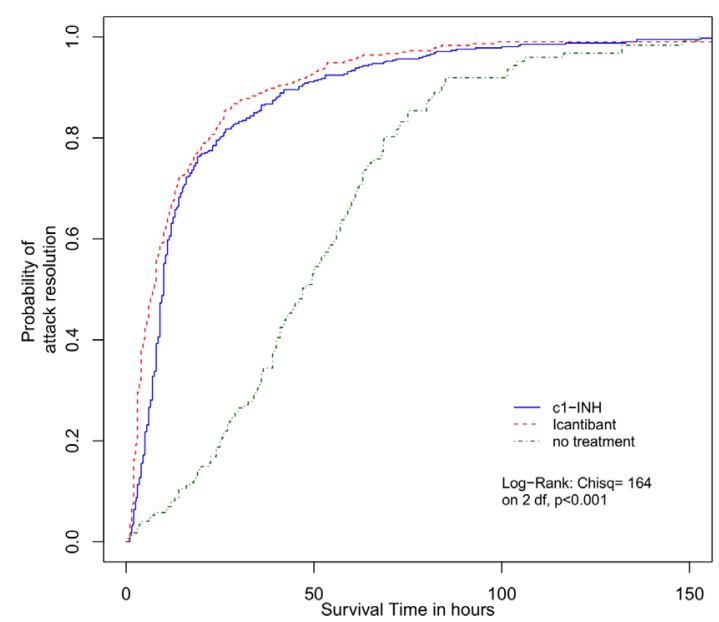

B

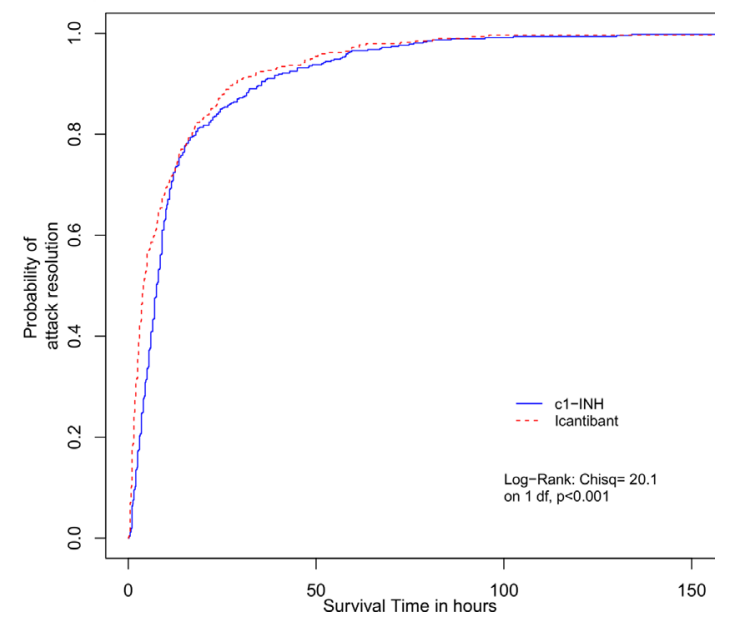

Figure 2 Kaplan-Meier curves of attack resolution from onset of symptoms (A) and treatment administration (B). C1-INH, C1inhibitor.

an attack with icatibant was still $54 \%$ higher than pdC1-INH (figure 3).

Facial, laryngeal and abdominal attacks tended to generate higher costs than cutaneous attacks $(22 \%, 16 \%$ and $11 \%$, respectively). Severe and moderate attacks were $30 \%$ and $17 \%$ more expensive than mild attacks. Lastly, the time between onset of symptoms and treatment administration was not found to be a significant predictor of higher or lower costs.

\begin{tabular}{|c|c|c|}
\hline & $\begin{array}{l}\text { Time from } \\
\text { treatment to attack } \\
\text { resolution HR } \\
(95 \% \mathrm{Cl})\end{array}$ & $\begin{array}{l}\text { Time from } \\
\text { symptoms onset to } \\
\text { attack resolution HR } \\
(95 \% \mathrm{Cl})\end{array}$ \\
\hline \multicolumn{3}{|l|}{ Treatment } \\
\hline $\begin{array}{l}\text { Icatibant versus } \\
\text { pdC1-INH }\end{array}$ & $1.31(1.14$ to 1.51$)$ & \\
\hline $\begin{array}{l}\text { pdC1-INH versus no } \\
\text { treatment }\end{array}$ & & 2.45 (2.05 to 2.93$)$ \\
\hline $\begin{array}{l}\text { Icatibant versus no } \\
\text { treatment }\end{array}$ & & 3.16 (2.62 to 3.80$)$ \\
\hline Time to treatment & $0.98(0.97$ to 0.99$)$ & \\
\hline \multicolumn{3}{|c|}{ Attack severity (vs low severity) } \\
\hline Moderate & 1.01 (0.84 to 1.22$)$ & $1.02(0.87$ to 1.19$)$ \\
\hline High & 0.83 (0.67 to 1.03$)$ & 0.85 (0.70 to 1.02$)$ \\
\hline \multicolumn{3}{|c|}{ Patients age (vs age $0-24$ years) } \\
\hline $25-55$ years & $1.46(1.2$ to 1.77$)$ & 1.24 (1.04 to 1.48$)$ \\
\hline$>55$ years & $1.42(1.1$ to 1.84$)$ & 1.25 (0.98 to 1.56$)$ \\
\hline \multicolumn{3}{|c|}{ Attack site (vs cutaneous/peripheral attack) } \\
\hline Abdominal & 0.94 (0.81 to 1.09$)$ & 0.91 (0.79 to 1.04$)$ \\
\hline Face & 1.07 (0.79 to 1.44$)$ & $1.18(0.89$ to 1.57$)$ \\
\hline Throat larynx & 1.44 (1.07 to 1.95$)$ & $1.68(1.25$ to 2.25$)$ \\
\hline On prophylaxis & $0.88(0.75$ to 1.03$)$ & $1.01(0.89$ to 1.17$)$ \\
\hline
\end{tabular}

pdC1-INH, plasma derived C1-inhibitor.

p> 0.05 is shown in bold.

\section{DISCUSSION}

This study analyses data from a population of 167 patients with C1-INH-HAE, and reports detailed information on 1508 attacks, including treatment behaviour, attack duration, received ODTs and use of other healthcare services. On average patients reported 11 attacks per year confirming the results of a previous prospective study on 103 patients, that found an average of 10 attacks during the same observation period..$^{37}$ The total cost per year in the population was $€ 1.58$ million, equivalent to slightly more than $€ 11900$ per patient per year. The average cost for a single attack was $€ 1183$ ( $\mathrm{SD}=€ 789$ ), with variations mainly depending on ODT drug, attack severity and attack site. Particularly the cost for an attack treated with icatibant was found to be $€ 1651$ (SD $€ 469$ ), or $54 \%$ higher than pdC1-INH after controlling for attack site and severity. On the effectiveness side, this study confirms the efficacy of both ODTs on shortening attack duration. ${ }^{163839}$ In fact, remission rates after receiving icatibant and pdC1-INH were found to be 2.5 times and 3 times faster compared with no treatment. In addition, data showed that icatibant improved the chance of remission by $31 \%$ compared with pdC1-INH (HR 1.31, 95\% CI 1.14 to 1.51 ). Nonetheless, a certain variability in the dosing of pdC1-INH was found within the same patients across attacks. Although patients' weight was not available in the data, this result seems to support the authors' experience that, despite weight-based recommended doses, patients treating attacks with pdC1-INH tend to self-administrate the minimum dose at onset (500 IU) and to take further vials only if the attack persists or progresses in severity.

There is a paucity of studies exploring attack frequency and treatment costs based on prospectively collected data at the attack level. A recent multicentre cluster-randomised controlled study ${ }^{40}$ investigated the impact on resource use and quality-adjusted life years (QALYs) of a dedicated telephone care-management service for patients with C1-INH-HAE. Results showed that the 
coefficients $[95 \% \mathrm{Cl}]$

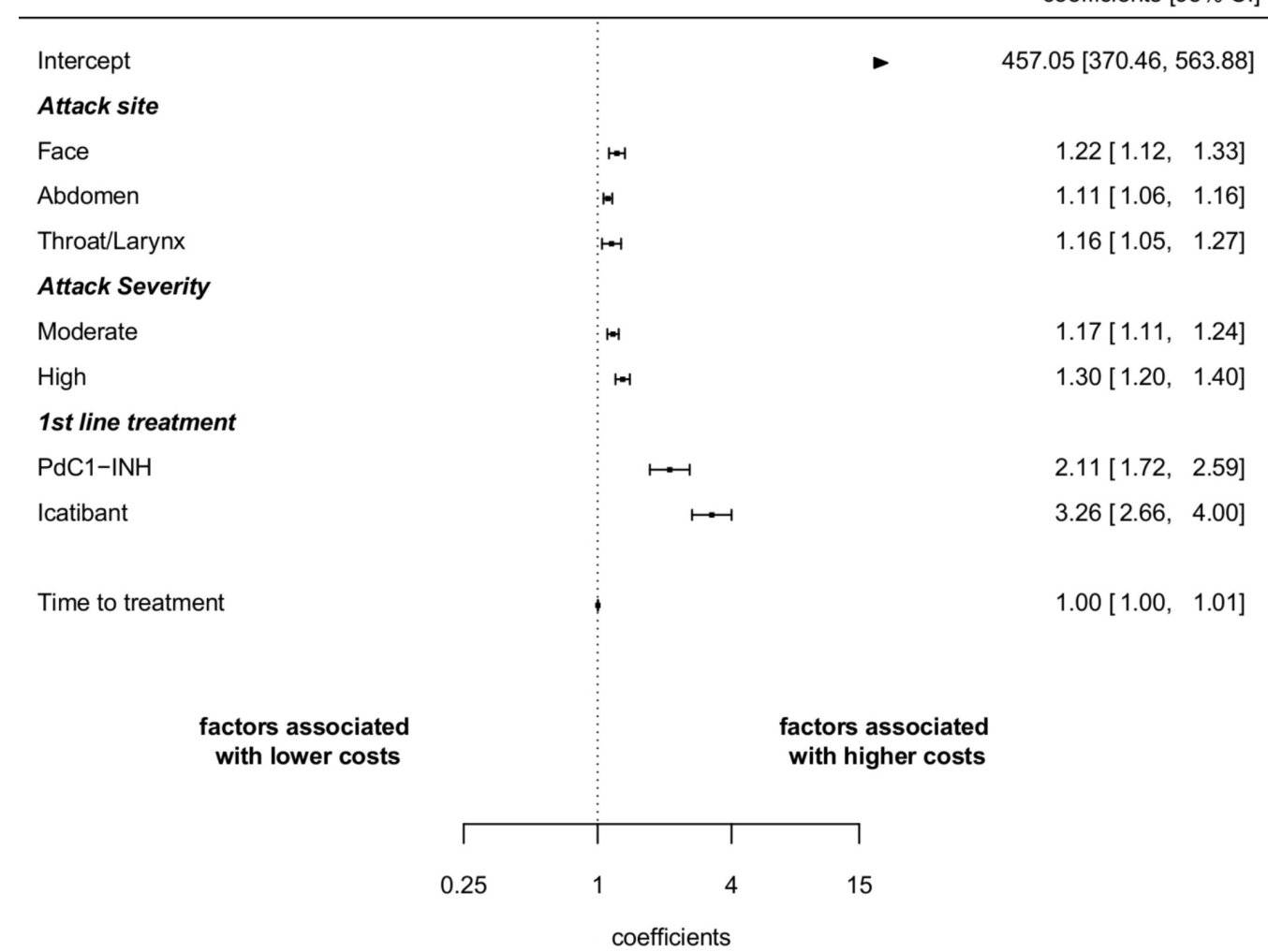

Figure 3 Determinants of the cost of attacks. Coefficients $(95 \% \mathrm{Cl})$ from cost model. pdC1-INH, plasma derived C1-inhibitor.

intervention significantly reduced the number of hospital admission in comparison with usual practice, thus leading to a reduction in overall hospital costs. The study also estimated lower expected drug costs over 2 years $(\$ 11874$ vs \$12 496) and improvements in QALYs gained (1.42 vs 1.40$)$, although these latter estimates were not statistically significant. Previous studies relied on a retrospective surveys to infer the average cost of acute attacks during 1 year. ${ }^{41} 42$ In Italy, estimated healthcare direct costs from a survey of 17 patients using pdC1-INH at home were found to be almost double than the results of this study (€26522 per patient per year). This difference is mainly attributable to different costs of ODTs, that may in turn be justified by different estimates in the number of attacks (not reported in the study).

In addition, while there exist clinical studies comparing icatibant and pdC1-INH to placebo, no direct evidence was found on the relative effectiveness of available ODTs. Since heterogeneous study protocols and small study populations hamper indirect and mixed treatment comparisons, this study provides useful insights on the real-world relative effectiveness of pdC1-INH compared with icatibant. This study has also several limitations. Since treatment for acute attacks was mostly self-administered at home, there is no way to control for patients taking ODTs inappropriately or in the absence of a true C1-INH-HAE attack. In addition, although all patients were recommended to report attacks at occurrence, reporting rates may have been different across patients, for example, depending on severity and attack frequency.
Consequently, it may be that the aggregated and per patient costs of attacks are not representative of the whole patient population in Italy. In addition, since the data did not include information on weight, the present study can only provide educated guesses on the potential patterns of undertreatment with pdC1-INH and its role on treatment costs and efficacy. A modified version of the report form has been implemented since January 2018 and will contribute to better explain patients' behaviours. A further limitation of the data used in this study is that no adjustments were possible for patient characteristics other than age and sex. Therefore, a word of caution is warranted in that differences in treatment costs and outcomes may be partially due to original imbalances in patients groups. Lastly, as with all registry data, recall bias issues may exist. Despite being a potential source of concern, these data still provide valuable information on a large sample of patients and attacks that would not have been feasible to obtain through other studies with more rigid data collection protocols.

The results of the study provide valuable insights that are relevant to clinicians and policy-makers. First, despite recommendations from clinical guidelines to treat all attacks at onset, $21 \%$ of the reported attacks were not treated with any available ODT. Second, average time from onset of symptoms to treatment was about 4 hours, and data suggest that this delay is associated with a small but significant negative effect on remission rates, confirming clinical recommendations on the need for early treatment. However, one of the possible reasons for 
this delay is the sneaky onset of attacks that creates uncertainty on symptoms' interpretation, resulting in patients taking treatment when the attack severity has already progressed.

The observed variability in the dosing of pd-C1-INH largely explains the differences in costs across treatments, and it raises questions on whether the differential in effectiveness found between pdC1-INH and icatibant is due to inappropriate dosage with pdC1-INH. Indeed, a previous meta-analysis of controlled studies using plasma-derived and recombinant C1-INH showed a direct correlation between doses and efficacy. ${ }^{43}$ Further research is needed to better explore potential patterns of undertreatment with pdC1-INH and its main determinants.

Lastly, $22 \%$ of the study population was treated with LTP during the observation period. Of these, almost $70 \%$ reported less than 10 attacks per year. Considering that in the study population LTP with attenuated androgens was prescribed only to patients with two or more attacks per months, these data provide further evidence in support to the effectiveness of LTP with attenuated androgens. Until 2010, attenuated androgens have been the only effective approach and were largely used despite significant side effects. ${ }^{21}$ More recently, new studies supported the introduction of regular intravenous infusions of pdC1-INH (Cinryze).${ }^{17}$ This approach massively replaced attenuated androgens for LTP in the USA, whereas in Italy, its use remains limited. Nonetheless, LTP with Cinryze is far more expensive than attenuated androgens ${ }^{44}$ calling for appropriate cost-effectiveness studies to demonstrate its value for money and to inform clinical guidelines. The results presented in this study may be used to populate future economic evaluations to inform decision-making on both prophylactic and ODTs.

\section{CONCLUSION}

The study defined the direct costs and relative efficacy of ODTs in an Italian population of patients with C1-INH-HAE. Both icatibant and pdC1-INH significantly reduced attack duration compared with no treatment. Treatment with icatibant was more effective than pdC1-INH, but also significantly more expensive. Further research is needed to understand the role played by treatment behaviours and specifically suboptimal dosing of pdC1-INH.

Acknowledgements We thank the patients who contributed to the collection of data. Support for the electronic data registry and data process management was provided by RdM and the team of cloud-R.

Contributors The authors responsibilities were as follows: CF, FP, RT and MC designed the research. CF and FP conducted the research and analysed data; $\mathrm{CF}$ and FP wrote the manuscript; $\mathrm{VC}, \mathrm{LB}, \mathrm{AZ}$ and $\mathrm{AG}$ had a primary role in the acquisition and first processing of the registry data and integration with other sources (cost data from national databases). CF, FP, RT and MC had primary responsibility for the final content. All authors read and approved the final manuscript. CF, FP and MC are the guarantors of the study. All authors, external and internal, had full access to all data (including statistical reports and tables) in the study and took responsibility for the integrity of the data and the accuracy of the data analysis.
Funding The authors have not declared a specific grant for this research from any funding agency in the public, commercial or not-for-profit sectors.

Competing interests None declared.

Patient consent Not required.

Ethics approval The local ethics committee approved the study protocol (prot no 3431/2016, 26 February 2016).

Provenance and peer review Not commissioned; externally peer reviewed.

Data sharing statement No additional data are available. Code used for costs and effects analysis is available on request to authors.

Open access This is an open access article distributed in accordance with the Creative Commons Attribution Non Commercial (CC BY-NC 4.0) license, which permits others to distribute, remix, adapt, build upon this work non-commercially, and license their derivative works on different terms, provided the original work is properly cited, appropriate credit is given, any changes made indicated, and the use is non-commercial. See: http://creativecommons.org/licenses/by-nc/4.0/.

\section{REFERENCES}

1. Frank M. Urticaria and angioedema. In: Goldman L, Bennett JC, eds. Cecil Textbook of Medicine. 21st edn. Philadelphia, PA, USA, 2000.

2. Talavera A, Larraona JL, Ramos JL, et al. Hereditary angioedema: an infrequent cause of abdominal pain with ascites. Am J Gastroenterol 1995:90:471-4.

3. Roche O, Blanch A, Caballero T, et al. Hereditary angioedema due to $\mathrm{C} 1$ inhibitor deficiency: patient registry and approach to the prevalence in Spain. Annals of Allergy, Asthma \& Immunology 2005;94:498-503.

4. Bygum A. Hereditary angio-oedema in Denmark: a nationwide survey. Br J Dermatol 2009;161:1153-8.

5. Zanichelli A, Arcoleo F, Barca MP, et al. A nationwide survey of hereditary angioedema due to $\mathrm{C} 1$ inhibitor deficiency in Italy. Orphanet J Rare Dis 2015;10:11.

6. Caccia S, Suffritti C, Cicardi M. Pathophysiology of hereditary angioedema. Pediatr Allergy Immunol Pulmonol 2014;27:159-63.

7. Nussberger J, Cugno M, Cicardi M, et al. Local bradykinin generation in hereditary angioedema. J Allergy Clin Immunol 1999;104:1321-2.

8. Aygören-Pürsün $\mathrm{E}$, Bygum $\mathrm{A}$, Beusterien $\mathrm{K}$, et al. Socioeconomic burden of hereditary angioedema: results from the hereditary angioedema burden of illness study in Europe. Orphanet $J$ Rare Dis 2014;9:99.

9. Banerji A, Busse P, Christiansen SC, et al. Current state of hereditary angioedema management: a patient survey. Allergy Asthma Proc 2015;36:213-7.

10. Lumry WR. Hereditary angioedema: the economics of treatment of an orphan disease. Front Med 2018;5:22.

11. Wu MA, Zanichelli A, Mansi M, et al. Current treatment options for hereditary angioedema due to $\mathrm{C} 1$ inhibitor deficiency. Expert Opin Pharmacother 2016;17:27-40.

12. Longhurst $\mathrm{H}$, Cicardi M, Craig $\mathrm{T}$, et al. Prevention of hereditary angioedema attacks with a subcutaneous C1 Inhibitor. N Engl J Med 2017;376:1131-40.

13. Banerji A, Busse P, Shennak M, et al. Inhibiting plasma kallikrein for hereditary angioedema prophylaxis. N Engl J Med 2017;376:717-28.

14. Zuraw B, Cicardi M, Levy RJ, et al. Recombinant human C1-inhibitor for the treatment of acute angioedema attacks in patients with hereditary angioedema. J Allergy Clin Immunol 2010;126:821-7.

15. Cicardi M, Levy RJ, McNeil DL, et al. Ecallantide for the treatment of acute attacks in hereditary angioedema. $N$ Engl J Med 2010;363:523-31.

16. Cicardi M, Banerji A, Bracho F, et al. Icatibant, a new bradykininreceptor antagonist, in hereditary angioedema. N Engl J Med 2010;363:532-41.

17. Zuraw BL, Busse PJ, White M, et al. Nanofiltered C1 inhibitor concentrate for treatment of hereditary angioedema. $N$ Engl J Med 2010;363:513-22.

18. Cicardi M, Bork K, Caballero T, et al. Evidence-based recommendations for the therapeutic management of angioedema owing to hereditary $\mathrm{C} 1$ inhibitor deficiency: consensus report of an International Working Group. Allergy 2012;67:147-57.

19. Zanichelli A, Mansi M, Azin GM, et al. Efficacy of on-demand treatment in reducing morbidity in patients with hereditary angioedema due to C1 inhibitor deficiency. Allergy 2015;70:1553-8.

20. Gelfand JA, Sherins RJ, Alling DW, et al. Treatment of hereditary angioedema with danazol. $N$ Engl J Med Overseas Ed 1976;295:1444-8. 
21. Riedl MA. Critical appraisal of androgen use in hereditary angioedema: a systematic review. Ann Allergy Asthma Immunol 2015;114:281-8.

22. Gazzetta Ufficiale della Repubblica Italiana 23 Maggio. 2013. http:// www.gazzettaufficiale.it/eli/gu/2013/05/23/119/sg/pdf

23. Christiansen SC, Bygum A, Banerji A, et al. Before and after, the impact of available on-demand treatment for HAE. Allergy Asthma Proc 2015;36:145-50.

24. Morrow T. Insurers will find icatibant lifesaving but expensive treatment. Managed care once again faces the all-too-familiar debate about cost and benefit. Manag Care 2011;20:63-4.

25. Cohen JP, Felix A. Are payers treating orphan drugs differently? J Mark Access Health Policy 2014;2:23513.

26. Kaplan EL, Meier P. Nonparametric estimation from incomplete observations. J Am Stat Assoc 1958;53:457-81.

27. Bozdogan H. Model selection and Akaike's Information Criterion (AIC): the general theory and its analytical extensions. Psychometrika 1987;52:345-70.

28. Italian Ministry of Health. Remunerazione delle prestazioni di assistenza ospedaliera per acuti, assistenza ospedaliera di riabilitazione e di lungodegenza post acuzie e di assistenza specialistica ambulatoriale, 2012.

29. AIFA. Determinazione 25 maggio 2009. Regime di rimborsabilita' e prezzo di vendita del medicinale per uso umano «Firazyr». (09A06483). 2009. http://www.gazzettaufficiale.it/atto/serie_generale/ caricaDettaglioAtto/originario?atto.dataPubblicazioneGazzetta=200906-18\&atto.codiceRedazionale=09A06483\&elenco30giorni=false

30. AIFA. Determina 29 Settembre 2016. Regime di rimborsabilita' e prezzo a seguito di nuove indicazioni terapeutiche del medicinale per uso umano «Berinert». (Determina n. 1352/2016). 2016. http:// www.gazzettaufficiale.it/atto/serie_generale/caricaDettaglioAtto/ originario?atto.dataPubblicazioneGazzetta=2016-10-25\&atto. codiceRedazionale $=16$ A07603\&elenco30giorni=true

31. Nixon RM, Thompson SG. Parametric modelling of cost data in medical studies. Stat Med 2004;23:1311-31.

32. Gelman A, Hill J. Data analysis using regression and multilevel/ hierarchical models. Cambridge, New York: Cambridge University Press, 2007.

33. Heidelberger P. ACM PW-C of the, 1981 undefined. A spectral method for confidence interval generation and run length control in simulations. https://dl.acm.org/citation.cfm? $i d=358630$ (accessed 5 Feb 2018).
34. Gelman A, Rubin DB. Inference from iterative simulation using multiple sequences. Statistical Science 1992;7:457-72.

35. Cooper NJ, Lambert PC, Abrams KR, et al. Predicting costs over time using Bayesian Markov chain Monte Carlo methods: an application to early inflammatory polyarthritis. Health Econ 2007;16:37-56.

36. Duan N. Smearing estimate: a nonparametric retransformation method. J Am Stat Assoc 1983;78:605-10.

37. Zanichelli A, Vacchini R, Badini M, et al. Standard care impact on angioedema because of hereditary $\mathrm{C} 1$ inhibitor deficiency: a 21 -month prospective study in a cohort of 103 patients. Allergy 2011;66:192-6

38. Lumry W, Li H, Levy R, et al. Randomized placebo-controlled trial of the bradykinin $\mathrm{B} 2$ receptor antagonist icatibant for the treatment of acute attacks of hereditary angioedema: the FAST-3 trial. http://www. annallergy.org/article/S1081-1206(11)00658-2/abstract (accessed 5 Feb 2018).

39. De Serres J, Gröner A, Lindner J. Safety and efficacy of pasteurized C1 inhibitor concentrate (Berinert $\mathrm{P}$ ) in hereditary angioedema: a review. jean.de.serres@aventis.com. Transfus Apher Sci 2003;29:247-54.

40. Javaud N, Fain O, Durand-Zaleski I, et al. Specialist advice support for management of severe hereditary angioedema attacks: a multicenter cluster-randomized controlled trial. Ann Emerg Med 2018. doi: 10.1016/j.annemergmed.2018.01.053. [Epub ahead of print 2 Mar 2018].

41. Wilson DA, Bork K, Shea EP, et al. Economic costs associated with acute attacks and long-term management of hereditary angioedema. Ann Allergy Asthma Immunol 2010;104:314-20.

42. Petraroli A, Squeglia V, Di Paola N, et al. Home therapy with plasma-derived C1 inhibitor: a strategy to improve clinical outcomes and costs in hereditary angioedema. Int Arch Allergy Immunol 2015;166:259-66.

43. Hack CE, Relan A, van Amersfoort ES, et al. Target levels of functional $\mathrm{C} 1$-inhibitor in hereditary angioedema. Allergy 2012;67:123-30.

44. Rasmussen ER, Aagaard L, Bygum A. Real-life experience with longterm prophylactic $\mathrm{C} 1$ inhibitor concentrate treatment of patients with hereditary angioedema: Effectiveness and cost. Ann Allergy Asthma Immunol 2016;116:476-7. 